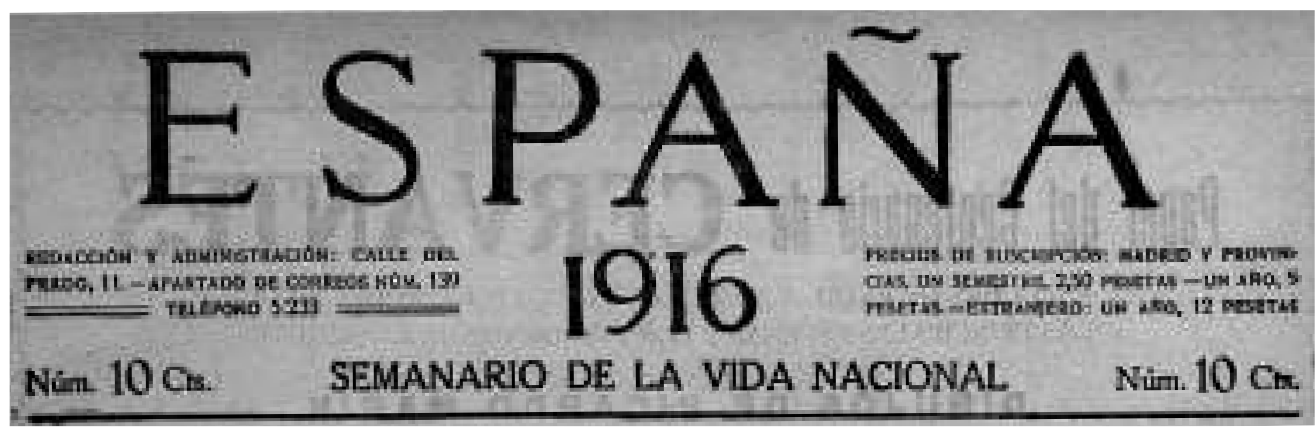

\title{
LOS MANICOMIOS ESPAÑOLES
}

\section{POR EL \\ Dr. Gonzalo R. Lafora}

El atraso que el aislamiento europeo y el misoneísmo de las pasadas generaciones de españoles imprimieron en muchas de nuestras instituciones (universidades, escuelas, instituciones penitenciarias, centros de beneficencia, etcétera), se manifiesta como en ninguna otra en los manicomios, refugios de desgraciados a quienes la sociedad quiere olvidar o ignorar. Muchos de estos establecimientos provinciales asientan en vetustos edificios de tres y cuatro siglos, insalubres, sucios y abandonados, que contrastan por su pobreza con otros vecinos de construcción moderna y suntuosa y habitados por ricas instituciones religiosas o dedicados a la vistosa fiesta nacional. Todos aquéllos tienen una tradición gloriosa: ora fueron fundados por un santo varón, ora alojaron a otro en periodos de perturbación mental, o bien en ellos se iniciaron métodos de tratamiento muy humanitarios para una época ya remota. Hoy, sin embargo, no son más que lugares de atraso y de vergüenza nacional. Su organización entera se mantiene inmutable y de acuerdo con la época de creación. Ninguno de los avances del siglo XIX han impreso en ellos la más leve huella, y de esto son principales culpables los psiquia- tras españoles que, ignorantes 0 abandonados, no han levantado nunca una voz de protesta que llegase hasta nuestros gobernantes.

En estas notas queremos fijar la época histórica en que aun se desenvuelven en España este género de instituciones. Para ello tendremos que señalar ciertas atrocidades increíbles, y tememos que nuestro atrevimiento y ansia de renovación nos traiga denuestos de varias partes; pero es preciso contribuir a que desaparezca este oprobio, que en el Congreso Internacional de Medicina celebrado en Madrid en 1903, originó innumerables críticas y artículos de los profesores extranjeros.

En el interesante libro de Bernard Hart sobre la "Psicología de la locura" (The psychology of insanity, Cambridge, 1912), hace este autor un breve resumen histórico sobre las diferentes concepciones de la locura que ha tenido la humanidad, y las clasifica en cuatro: demonológica, política, fisiológica y psicológica. Cada una de estas concepciones ha llevado como consecuencia una diferente conducta de la sociedad para con los alienados.

En la concepción demonológica de las primeras edades, que toma gran vigor en la

Rev. Asoc. Esp. Neuropsiq., 2011; 31 (112), 777-789. doi: 10.4321/S0211-57352011000400014 
Edad Media, la locura es considerada como la manifestación de un ser espiritual, divino o demoníaco (variable según las creencias religiosas de la época o país), el cual habita el cuerpo del paciente 0 le influencia desde fuera. El loco es, pues, ensalzado o perseguido, según la clase de espíritu que sus contemporáneos suponen le influencia.

Aparece luego la concepción política, en la que la sociedad sólo se preocupa de librarse del alienado, encarcelándole 0 recluyéndole ${ }^{1}$. Ya no cree que sea un poseído del diablo; pero tampoco le concede ningún derecho o consideración social.

A principios del siglo XIX, con Pinel y Esquirol en Francia, y con Tuke y Conolly en Inglaterra toma cuerpo la concepción fisiológica, ya iniciada por Hipócrates más de mil años, antes, pero abandonada por el oscurantismo medioeval. En esta concepción fisiológica, el loco es considerado como un enfermo del cerebro (órgano donde radica el pensamiento), y la sociedad le concede el derecho a ser tratado como un ser humano. Conviértense entonces los manicomios en sitios de orden y confort, y el paciente es cuidado y estudiado científicamente. Es la época del humanitarismo y cientifismo, en que se prohíben los métodos coercitivos y empieza a iniciarse el no-restraint de los ingleses.

Como una derivación científica de esta última concepción y para explicar ciertos fenómenos anormales de las psicosis funcionales, surge recientemente, con Janet, Kraepelin, Freud, Bleuler y otros, la modernísima concepción psicológica, la cual investiga los mecanismos mentales en un sentido puramente psicogénico.

Veamos ahora en cuál de estas fases se encuentran nuestras instituciones oficiales para alienados. De nuestras visitas a varios manicomios provinciales (los de Cádiz, Grana- da, Toledo, Madrid y Valencia), creemos poder afirmar que nos encontramos todavía en plena concepción política. Escogeremos algunas de nuestras numerosas fotografias para demostrar nuestro aserto.

Hogarth, que ha descrito plásticamente la época de la concepción política, dice así: "Los hombres estaban cubiertos de suciedad, encerrados en celdas de piedra, frías, húmedas, sin aire y luz y con un lecho de paja, que rara vez era renovado y con frecuencia se convertía en un foco infeccioso; horribles mazmorras, donde deberíamos tener escrúpulo de alojar a los más viles animales. El loco arrojado en estos receptáculos estaba a merced de sus guardianes, y estos guardianes eran licenciados de presidio. Los desgraciados pacientes eran cargados de cadenas y atados como esclavos de galeras".

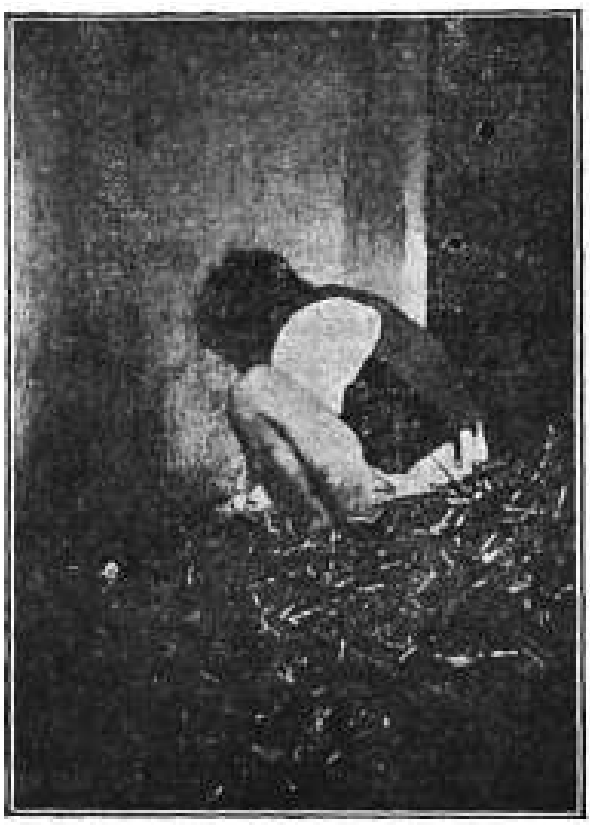

MANICOMIO PROVINCIAL. DE ORANADA Enfermo medio densude sobrejumperhe de pria, -Fig. 1.

\footnotetext{
1 Recuérdense las famosas torres, como la de Leipzig, donde los locos encarcelados servían de entretenimiento a los niños y paseantes del jardín público.
} 


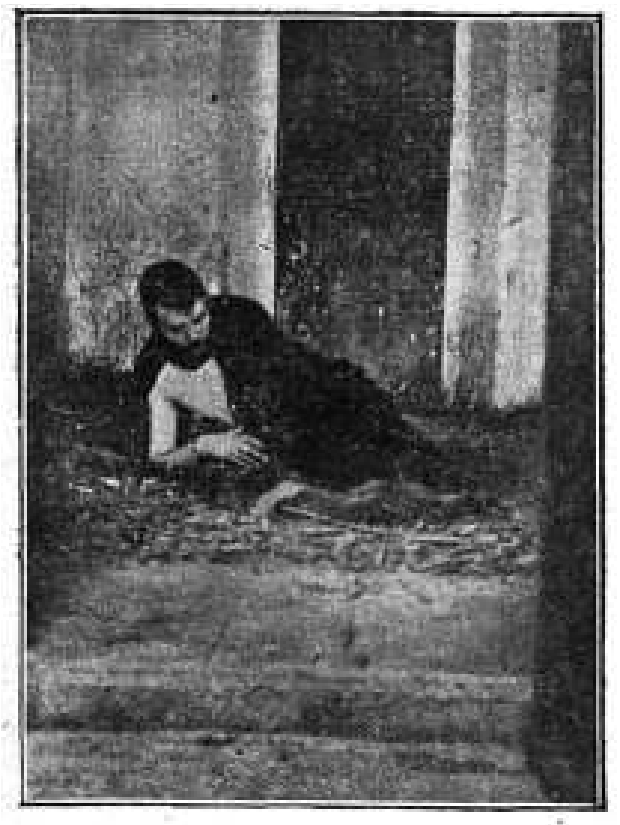

MANICOMIO PROVINCIAL DE GRANADA

Celila con piso de pledra $y$ leebo de paja. El enfermo esta cublerio ânicamesie eỏ una manta,-Fig. 2 .

Esta espeluznante descripción es casi aplicable a las mazmorras que hemos visto en el Manicomio Provincial de Granada, del que proceden las dos primeras fotografias, obtenidas en el último Abril (v. figs. 1 y 2). Un ceñudo guardián con recio manojo de enormes llaves nos va abriendo las sólidas puertas de estas celdas-calabozos. El piso es de piedra con un canal para el desagüe. En un lado, sobre un montón de paja, que hace de lecho, yace un enfermo casi desnudo, lleno de suciedad y completamente abandonado. Cada puerta tiene una ventanilla enrejada para que los guardianes puedan observar a los recluidos. Abundan los motivos para agua-fuertes a la manera de Goya. Tiene razón Hogarth al decir que no tenemos a los animales en peores condiciones. Este famoso Manicomio de Granada, bello edificio del Renacimiento, fue visitado en 1903 por el célebre psiquiatra alemán Kraepelin, quien salió horrorizado al revivir en pocas horas las descripciones de manicomios de siglos pasados. Han transcurrido trece años más y todo permanece lo mismo.

La supresión de cadenas, esposas y otros brutales medios coercitivos que se impuso en Europa hace ya muchos años, se desconoce aún en los manicomios oficiales españoles. Véanse dos fotografias (figs. 3 y 4) obtenidas por nosotros este verano en el Manicomio Provincial de Valencia, uno de los más gloriosos y quizás de los más limpios que poseemos. En una aparece un joven demente, cubierto con un saco de amplias bocamangas, con los pies descalzos y enlazados por una cadena de recios anillos que sólo le permiten andar a saltitos. En la otra, un viejo tiene un cinturón metálico, del que derivan dos cadenas que inmovilizan sus manos. En ambas fotografias vemos a los típicos guardianes de nuestros manicomios, hombres ineducados, sucios, desgarbados y de una jovialidad amable. Los domingos conducen grupos de locos a pre-

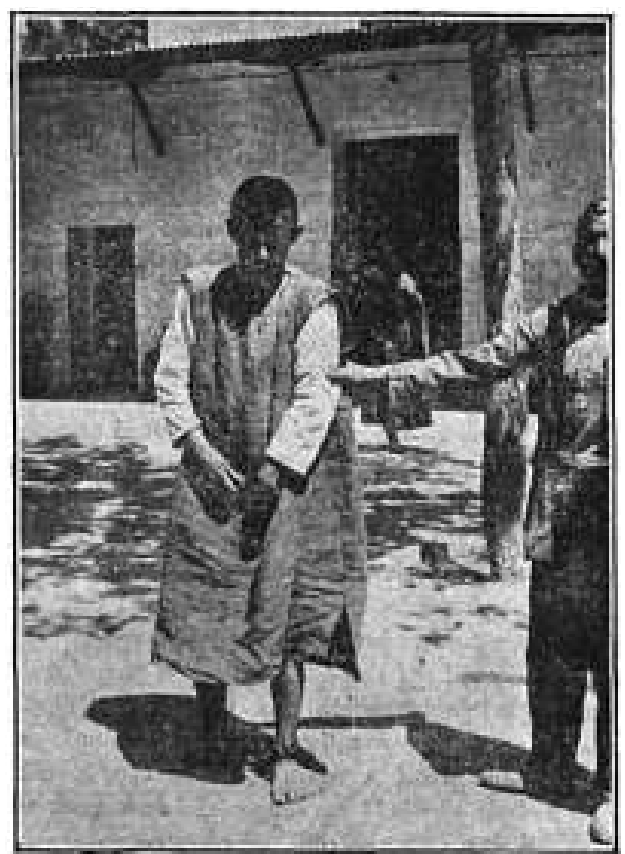

MANICOMIO PROVINCIAL DF VAIENCIA Fntermo con los pies encadenados,-Fig. 8 


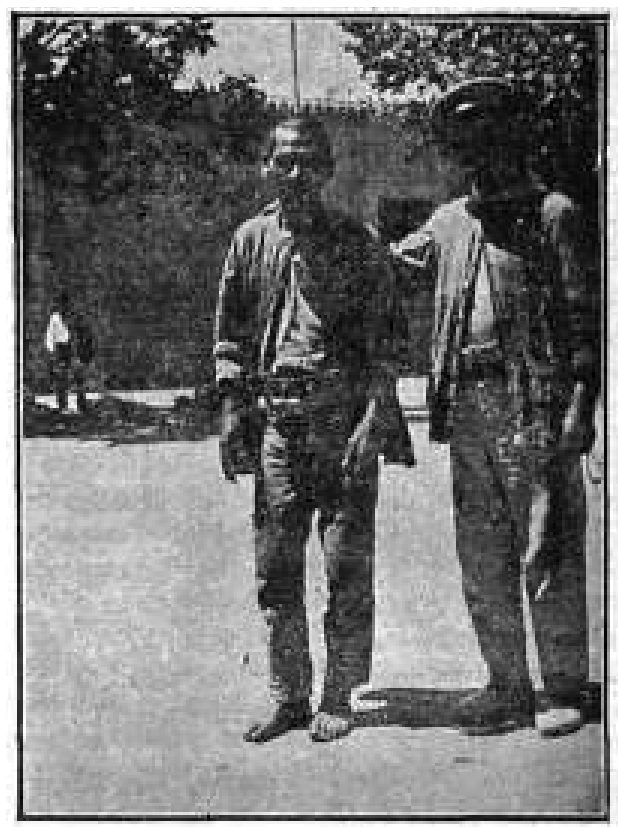

MANICOMIO PROVINCIAL. DE VALENCIA

Entermo con cisturét de hierro, al que estan eacadenndas las manos, - Fig. 4 .

senciar la corrida de toros, y dicen que disfrutan mucho del espectáculo (!!!).

Del departamento de alienados del Hospital Provincial de Madrid, sólo diremos que permanece en el mismo estado que en la época de su fundación, hace ya dos siglos (1748). Allí no existen baños para los agitados, a los que se sujeta mediante camisas de fuerza, otro utensilio desterrado ya de todas partes. Cuando se empiezan a acumular los enfermos, una monja ordena traslados en masa a otros manicomios (al de Ciempozuelos o al de Valladolid), y los enfermos llegan a estos últimos con el único diag- nóstico de enagenación mental y sin ningún dato ulterior que sirva para diagnosticarlos científicamente. Aún reciente es la publicación de agresiones de sus guardianes a un alienado.

Sobre los demás establecimientos visitados, no es preciso tratar. Con pocas variantes, todos adolecen de los mismos defectos. No tienen suficiente personal de médicos y enfermeros, ni la preparación técnica de este personal es adecuada, ni hay departamento balneoterápico, ni, consecuentemente a los anteriores defectos, se suprimen los medios coercitivos medioevales. Esta es la situación, descrita escuetamente. A consecuencia de esta situación, los enfermos no son estudiados psiquiátricamente por los médicos, que sólo se ocupan de asistir a sus enfermedades intercurrentes. Rara vez encontraréis a un médico en el manicomio para que os lo pueda enseñar. Sorprende, por ti contrario, que cuando se visitan los departamentos de cirugia de cualquier hospital provincial, se encuentran en un estado de relativa modernidad, y es que los cirujanos exigen los progresos modernos, que no saben imponer los médicos y psiquiatras.

La modificación de las condiciones materiales de los establecimientos psiquiátricos exige grandes sumas, que en otros países se obtienen por donativos y mandas de particulares humanitarios. En el nuestro esta forma de caridad es casi desconocida, pues ha sido sustituida por las espléndidas fundaciones en favor de comunidades religiosas. Esperemos que esto cambie y que las Diputaciones no abandonen sus obligaciones benéficas.

\section{DR. GONZALO R. LAFORA} Madrid, Octubre 1916.

Reimpreso de: Gonzalo Rodríguez Lafora. Los manicomios Españoles. España. 12 oct. 1916. 90 : 8-10. 


\section{E. LA CORRESPONDENCIA DE ESPANA \\ LOS MANICOMIOS ESPAÑOLES}

Este mismo título lleva un artículo que el doctor Gonzalo R. Lafora publica en el último número del semanario España.

Se refiere á los manicomios de Granada, Valencia, Toledo y Cádiz. Las cosas que de ellos cuenta, las crueldades que en ellos vio, son de tal gravedad que, si están apreciadas con exactitud, como parece comprobado por las fotografias que acompañan al escrito, imponen no sólo una inmediata y radical reforma administrativa, sino una severa intervención judicial, que exija el tanto de culpa á quienes la tengan y les castigue con toda la dureza que el caso requiere.

Mil plácemes merece el Sr. Lafora por haber sacado á la vindicta pública este poco conocido aspecto de la desventura humana, en cuya rápida desaparición, seguramente, se han de interesar todas las almas honradas que se preocupan por tan dolorosos como ya inverosímiles hechos.

En lo que el Sr. Lafora no merece ser felicitado es en haber deducido de aislados casos particulares una conclusión general que abarca y desprestigia á todos los manicomios de España. Ésto, al menos, se desprende del título que encabeza su escrito, en cuyos párrafos finales se asegura que, "con pocas variantes, los demás establecimientos visitados adolecen de los mismos defectos".

Sin embargo, en Cataluña, Zaragoza, Navarra, provincias vascas, Valladolid, Palencia, Oviedo, Santiago, Ciempozuelos y en otra porción de puntos, existen manicomios que no son tan malos. Podrán estar montados con mayor ó menor modestia, en conformidad con los re- cursos, nunca muy abundantes, de que dispone cada provincia ó cada Municipio, y claro está que no han de ser modelos de perfección, que puedan rivalizar ventajosamente con los que el Sr. Lafora haya visto en Inglaterra, Francia ó Alemania, como nunca podrá competir el modestísimo hogar del obrero que gana tres pesetas con el confortable domicilio del burgués enriquecido ó con el lujoso palacio del aristócrata. Pero se encuentra en ellos alimentación sana, cama cómoda, aire y luz abundantes, abrigo para el cuerpo y caritativo afecto para el alma.

De todo esto creo yo que debió hablar también el Sr. Lafora, aun cuando no fuese más que para hacer resaltar aún el negro cuadro de cadenas, mazmorras é infierno que con tan estremecedoras tintas nos pinta en su artículo.

Hay, además otra razón de interés patriótico que obliga á todo buen español á imitar lo que hacen en otras partes, en esas cultas naciones por las que siempre estamos suspirando, y es que cuando se ven, en la precisión de señalar con el dedo alguna mancha que pueda menoscabar de prestigio de su país, se apresuran siempre á rodearla de términos de comparación que puedan servir de manto que la oculte á los ojos de los directamente interesados.

Si siempre hubiéramos procedido así no se tendría en el mundo el concepto tan depresivo que de nosotros se tiene.

Aparte de esto, el Sr. Lafora, en las quince líneas que dedica al "departamento de enajenados del Hospital Provincial» comete algunas inexactitudes y falsas interpretaciones, que, aun cuando carecen de importancia por si 
mismas, tienen bastante fuerza para alarmar al público, que no se detiene á analizar, y acepta $\mathrm{y}$ ve las cosas teñidas por de color que se las presenta.

Asegura, por ejemplo, que el departamento se encuentra en el mismo estado que en la época de su fundación.

Aunque soy, por desgracia, bastante viejo, no puedo recordar cómo estaba en tiempos de Carlos III, pero sí como se encontraba hace cuarenta y cinco años- Por aquel entonces, la situación de los locos era lamentable; vivian hacinados en salas poco ventiladas, con pavimento de tierra, sin patios adonde respirar y esparcirse, comiendo un rancho muy desagradable y durmiendo en camastros, sin más mullido que un flaco jergón que contenía unos puñados de paja de maíz o de trigo, frecuentemente podrida por las deyecciones. ¿Ocurre esto hoy? Hoy habitan los enfermos en salas amplias, llenas de luz y de aire, pavimentadas con lujo, duermen en camas con buenos colchones de muelles y de lana, disponen de amplios patios, en donde permanecer al aire libre. Comen bien y hasta existe en el departamento una cocina especial adonde se condimentan platos escogidos para los delicados ó los que no se avienen con el menú del establecimiento. ¿Se puede decir, con verdad, que están lo mismo que en la época de la fundación? Cuando se acumulan los enfermos, dice el Sr. Lafora, una monja ordena su traslado en masa á otros manicomios. Tampoco esto es cierto. La monja impersonal a que se refiere, debe ser la hermana de la caridad que presta sus servicios en el departamento. La aludida es una persona estimabilísima que sin mojigaterías ni hipócrita mansedumbre cumple sus deberes con una exactitud y abnegación como fuera muy de desear que hiciéramos todos. Conoce, además, hasta dónde llegan sus atributos y dentro de ellas se mantiene, sin que jamás si se le haya ocurrido ni meterse á ordenar traslados de locos, ni de nada.
Lo de la camisa de fuerza es una especie de coco con que se impresiona fácilmente al público. Último recuerdo de aquellos espantables medios coercitivos que Pinés consiguió desterrar en 1793; su sólo nombre lleva algo de repulsivo y brutal que aterra y contrista, $\mathrm{y}$, sin embargo, es muy difícil prescindir de ella en absoluto, más que para los agitados, para los agresivos y los inmorales. Constantemente hay en el departamento algún enfermo que con sus violencias y agresiones intranquiliza y consterna á sus compañeros de desgracia. Epilépticos delirantes, locos perseguidos, dementes de todas clases, degenerados inferiores, etc., hacen necesario alguna vez el uso de algún medio contentivo que evite los verdaderos peligros á que expone sus rápidas y virulentas impulsiones. Ninguno de entre ellos reúne las condiciones de la pomposamente llamada camisa de fuerza, que no es, en resumen, mas que una blusa de lona, cuyas mangas, más prolongadas que de ordinario, terminan en sendas cintas que, cruzándose en la parte anterior del cuerpo vienen á atarse en la espalda, impidiendo los movimientos demasiado amplios de los brazos é inutilizando el uso de las manos.

Un distinguido compañero nuestro y amigo particular del doctor Lafora, se encargó interinamente del departamento dé enajenados. El primer día que entró en el patio y vio á dos enfermos con la camisa de fuerza, se sublevaron en él todos los más altos y nobles sentimientos de humanitarismo, y ordenó, indignado, que inmediatamente se quitaran aquellos horribles artefactos, desterrados ya -como también dice el doctor Lafora- de todos los países civilizados. En efecto, así se hizo; pero verse libre el primer enfermo y sacudirle dos terribles bofetadas al humanitario compañero, todo fué uno.

No hay para qué decir que inmediatamente mandó restablecer las cosas como estaban, y desde aquella memorable fecha transige con la camisa de fuerza. 
Cierto que no existe instalación balneoterápica especial para el departamento; pero tabique por medio, ó muy inmediato á él, se encuentra la sección hidroterápica, fácilmente utilizable, siempre que el caso lo requiere.

Que los enfermos sean trasladados á otros manicomios sin que en la hoja que los acompaña se consigne más diagnóstico que el de "enajenación mental», obedece á que este departamento no tiene otra misión que la de comprobar si existe ó no la supuesta locura por la que fueron recluidos, y por eso se llama de Observación. Se sigue en esto la costumbre establecida por los ilustres frenópatas que me precedieron en el- departamento; pero aparte de ello, par" mi uso particular, llevo un libro registro, en el que están consignados los diagnósticos de todos los enfermos y la historia clínica de buen número de ellos. Todo lo cual pongo gustoso á la disposición del doctor Lafora.

Habla también de la "reciente publicación de agresiones de sus guardianes á un alienado".
Durante los ocho años qué llevo encargado del departamento, no ha llegado á mí noticia que se haya publicado nada por el estilo ni que haya existido el menor motivo que pudiera justificarlo.

Por último, para satisfacción del doctor Lafora, debo participarle que me ocupo actualmente en la confección de un informe técnico, referente á la instalación de un manicomio modelo, que la excelentísima Diputación provincial se propone construir en breve plazo.

Seguramente se necesitará entonces aumentar el personal facultativo, y podrá el doctor Lafora desarrollar ampliamente las aptitudes técnicas que tan excepcionalmente posee y que tan de menos echa en el actualmente en servicio.
R. PEREZ-VALDES. Octubre, 13, 1916.

Reimpreso de: R. Pérez Valdés. Los manicomios Españoles. La Correspondencia de España. 18 oct. 1916 ( (2ª ed.) 21434: 4. 

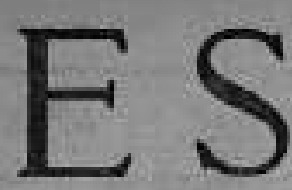

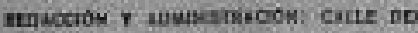

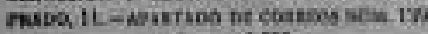
mavas mewo 5234

Num. $10 \mathrm{Cts}$

SEMANARIO DI

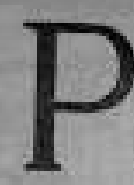

1916

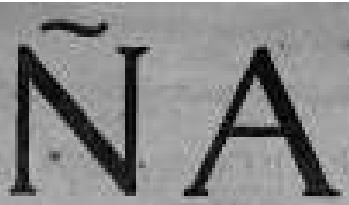

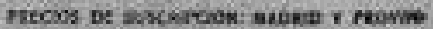

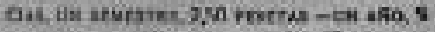

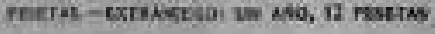

\section{EL MANICOMIO PROVINCIAL DE MADRID Réplica al Dr. Pérez Valdés}

El Dr. Pérez Valdés, director del Departamento de Dementes del Hospital Provincial, ha protestado en La Correspondencia de España del 18 de 0ctubre sobre las afirmaciones que respecto a dicho Departamento hice en el número penúltimo de ESPAÑA.

Debo recordar que en mi crítica no me dirigía para nada a él, ni le mencionaba. Tiene el Dr. Pérez Valdés una reputación científica bien cimentada como especialista que yo no he querido menoscabar, ni aunque lo hubiese querido lo habria conseguido. Conste, pues, y lo digo bien sinceramente, que no echo de menos en él, como erróneamente insinúa, aptitudes técnicas. Pero una cosa es la preparación técnica del Dr. Pérez Valdés, que yo respeto y alabo, y otra el estado y organización del Departamento, que critico por anticuada.

Me da la razón, sin embargo, en que se emplean las camisas de fuerza ${ }^{1}$, en que se envían los enfermos a otros manicomios con el único diagnóstico de "enagenación mental», $\mathrm{y}$ en que el Departamento no tiene sección balneoterápica. Insistamos sobre algunos de estos puntos.
Dice el Sr. Pérez Valdés que no se da más diagnóstico que el citado, porque la misión del Departamento es sólo comprobar la supuesta locura, pero que lleva privadamente un libro-registro con los diagnósticos y la historia clínica de los enfermos, el cual pone a mi disposición. Y yo pregunto: ¿Por qué ese hermetismo? ¿No cree el Dr. Pérez Valdés que esos documentos que me ofrece a mí, que no me sirven, serán utilísimos para el manicomio? Comprendería que no diese el diagnóstico, el cual no es más que una interpretación de los hechos; pero no que prive a sus colegas de los hechos observados, los cuales son inmutables y tienen mucha importancia para el diagnóstico. Así hacen todos los departamentos de observación del mundo que dan los datos y el diagnóstico probable, y algunos como el Psychopathic Ward,de Nueva York, la Psychíatrische Klinik, de Munich y la de Berlín, aportan además los datos que la policía al servicio de ellos les ha proporcionado respecto a los antecedentes familiares y género de vida del paciente, investigados por aquélla en la misma casa del enfermo. ¿Cómo no se ha organizado aún en Madrid esta perfecta colabo-

\footnotetext{
1 Esa blusa de lona con mangas prolongadas, que terminan en cimas que se atan a la espalda, impidiendo los movimientos de los brazos, que nos describe el doctor Pérez Valdés, es la conocida camisa de fuerza.
} 
ración informativa de la policía? Sólo merced a ésta puede el PsychopathicWard, de Nueva York, dar el diagnóstico probable en tres días, máximum de tiempo que la ley les permite retener los enfermos ${ }^{2}$.

Respecto a lo que dice de una instalación hidroterápica general vecina del Departamento, sólo !e diré que siento que no se utilice más, pues tengo entendido que a Ciempozuelos llegan los enfermos sucios, y además porque ahorraría, como sabe el Dr. Pérez Valdés mejor que yo, muchas camisas de fuerza. El uso de éstas que, entre humorismos, reputa de imprescindible en los agresivos e inmorales, ha sido suprimido en otros manicomios extranjeros, donde hay también: enfermos de estas categorias; pero para ello es preciso más vigilancia, o lo que es lo mismo, más personal de enfermeros y mejor preparación técnica de los mismos, y este es el personal sin aptitudes técnicas al que yo me refería en mi artículo anterior $^{3}$. Sorprende que en Madrid no haya aún una enseñanza especial para enfermeros de enagenados, ya en el Hospital Provincial o ya en la Facultad de Medicina.

Que ha habido hace algunos años una agresión a un enfermo por los enfermeros, comentadísima por la prensa diaria, lo vuelvo a afirmar, a pesar de la negativa del D. Pérez Valdés. Si es preciso lo demostraré repasando las colecciones de los periódicos. Fue un demente al que le fracturaron varias costillas y murió de resultas de ello.

Lo que dije respecto a una hermana de la candad que dispone de traslados, lo oí a persona que merece toda mi confianza y lo acepté así, pues supe que en estos traslados en masa se incluian a veces enfermos que habian permanecido menos tiempo del reglamentario (cuarenta días, según creo) en el Departamen- to de observación, y no podía creer que esto lo ordenase un colega. Por otra parte, no habiendo médico especialista residente, nada tiene de extraño este y otros excesos de atribuciones administrativas.

Por la defensa que del Departamento, como local, hace el Dr. Pérez Valdés, se infiere que no le parece mal como está. Siento disentir en esto también de su autorizada opinión. El local es oscuro y frío. En él se conservan ciertas celdas para agitados (que afortunadamente no se usan), de las que pidió Kraepelin fotografias para su Museo de la Historia del Manicomio. Los patios son muy reducidos, etc. Hace tiempo que habiamos querido hablar de esto, $\mathrm{y}$ con ese objeto hicimos un artículo que no quiso publicar La Tribuna (y lo perdió) porque podía parecer mal a la Diputación Provincial. Afortunadamente hay otras publicaciones independientes, como ESPAÑA, que no tienen esos miramientos.

No creemos que esto pueda ofender al doctor Pérez Valdés, que no es el culpable de ello, como tampoco lo son otros profesores del Hospital Provincial que tienen sus salas en sótanos y buhardillas y que no protestaron cuando alguien criticó este estado de cosas. Sólo podía sentirse ofendida por esto la Diputación, que no atiende debidamente al Hospital y a las mejoras necesarias en él. Cuando hace dos años un profesor de ese Hospital criticó en una revista el vergonzoso hacinamiento de enfermos infecciosos en las epidemias, se produjo un gran revuelo y hasta se le amenazó con un expediente si no daba unas explicaciones desvirtuando su aserto; pero aquel estímulo saludable de la crítica dio lugar a una reacción, cuyo resultado fue la creación del nuevo Departamento para infecciosos, con el auxilio de la caridad pública. Nosotros que no somos profesores del Hospital, podemos hablar con toda claridad y sin temor a

\footnotetext{
2 Tiene este Departamento unas 3.000 admisiones por año.

${ }^{3}$ Hay manicomios que han llegado a tener un enfermero por cada 364 enfermos. Por lo general, la proporción varía entre 1 por 6 a 1 por 10. En nuestro Departamento los enfermeros son pocos y nada instruidos en psiquiatría.
} 
expedientes que nos coarten la critica sobre el Departamento de observación.

No quiero terminar sin sacudirme la insinuación de mal español que deja escapar el doctor Pérez Valdés por mis desnudas descripciones de lo que he visto. Tenemos también los dos un concepto opuesto del patriotismo. Yo no creo que en el extranjero se hable mal de España por lo que decimos los españoles, sino por lo que ven, pasan y dicen los extranjeros que aquí vienen y sobre aquí escriben ${ }^{4}$. Tampoco creo que el silencio de nuestros males es nuestra mejor conducta. En mi permanencia en el extranjero he visto que allí se acusa con gran energia y claridad los defectos de las personas e instituciones. Bien recientes son las acusaciones durísimas contra un ministro inglés por suponérsele complicado en el negocio de la telegrafía sin hilos. Constantes son los artículos de crítica despiadada sobre los hombres y sus obras. Pero aquí en España se llama antipatriota al que rompe el silencio y señala una lacra.
¿Qué términos de comparación son posibles para endulzar nuestra descripción de lo visto en los manicomios? En los países vecinos no existe nada parecido y en los anglo-sajones menos aún. Los manicomios españoles que están montados más a la moderna son instituciones particulares, y yo sólo me ocupé de las oficiales y exclusivamente de las vistas por mi. Por lo demás, entre los Manicomios que cita el doctor Pérez Valdés hay algunos provinciales que están, según me han dicho, en esto parecido a los que yo describí, y otros son particulares. Como en éstos no se admiten enfermos indigentes, que es el problema que nos interesa, de ahí que no me ocupase de ellos, aunque he visitado varios. Conste, pues, que yo señalo defectos y atrasos increíbles, porque creo firmemente que así ejerzo más el verdadero patriotismo, el que sólo produce molestias y disgustos.

\section{DR. GONZALO R. LAFORA} 22 Octubre 1916.

\footnotetext{
4 Mucho más de lo dicho por nosotros se publicó en el extranjero sobre nuestros manicomios, entre otros por el profesor Lugaro, de Módena (Italia), a raíz del Congreso de 1903.
}

Reimpreso de: Gonzalo Rodríguez Lafora. El manicomio provincial de Madrid (Réplica al Dr. Pérez Valdés). España. 26 oct. 1916. 92: 8. 


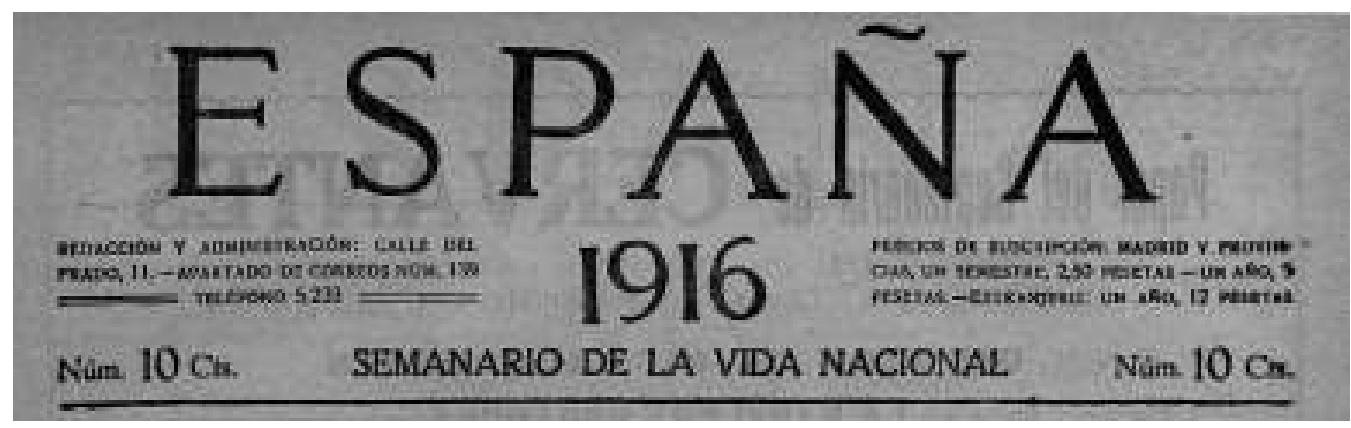

\section{MANICOMIOS ESPAÑOLES}

\section{Carta abierta al Dr. Gonzalo R. Lafora}

Con satisfacción he leído su artículo "Los Manicomios Españoles" publicado en el semanario ESPAÑA del día 12 del corriente mes, porque trata en él un asunto que demasiado olvidado lo dejan los que acostumbran a ocuparse de las cosas de interés público. Tiene usted mucha razón, es verdaderamente asquerosa la forma en que se presta el servicio de dementes en nuestros manicomios públicos.

No conozco ningún manicomio público español que haya salido completamente de esta época que usted, por boca de Bernard Hart, llama época de la concepción política de la locura, época que otro ilustre alienista apoda con el nombre de "Edad de Hierro". Los que más, habrán suprimido aparentemente los antihumanos medios coercitivos o de tortura, y digo aparentemente, porque en realidad lo que se ha hecho es sólo hacerlos algo más llevaderos y menos repugnantes en su aspecto, siendo en el fondo igualmente perjudiciales para los enfermos. Las fotografias que ilustran su artículo, creo que le sería fácil obtenerlas en cualquiera de nuestros manicomios, hasta en aquellos que tienen más apariencias de modernización.

Mucha satisfacción sentiría si después de publicarse estas cuartillas, alguien me replicara diciéndome que en su manicomio se tiene una concepción verdaderamente moderna de la locura, y que en buena consecuencia sistemáticamente so aplica el No Restraint.

Verdaderamente el atraso de nuestro servicio de asistencia a dementes es debido en gran parte a las reales condiciones de los edificios en que tenemos que albergar a estos enfermos, pero no considero que esta sea la causa principal; ésta, radica en nuestros sistemas de asistencia, radica en la organización defectuosa de todos nuestros servicios. Con edificios deficientes y anticuados podemos tratar relativamente bien a enfermos de esta clase; con más 0 menos perfección podemos implantar el tratamiento individual; con más o menos intensidad podemos utilizar el Encajamiento y la Psicoterapia, poderosos elementos terapéuticos modernos para esta clase de enfermedades. En cambio, con el sistema y con la organización actual, con el tratamiento colectivo que hoy se aplica, ni con los edificios más modernizados en su construcción, podiamos hacer obra positiva, el No Restraint y el Open-door serían de imposible aplicación.

Creo también, como usted, que del actual atraso de nuestro servicio tienen su tanto de culpa los médicos psiquiatras de nuestro país, puesto que si con más constancia se hubiesen 
interesado en mejorar nuestros servicios de asistencia de dementes, puede que no hubiesen logrado cambiar los manicomios actuales por otros más modernos, pero hubieran podido, sí, transformar el sistema de tratamiento, mejorar la organización de los manicomios y casi cambiar el ambiente de coerción y represión por otro más suave, más humano y más apropiado para la curación de los enfermos.

Pero si los médicos psiquiatras tienen su tanto de culpa en este asunto, también tienen sus motivos de disculpa, puesto que muchos de ellos no pueden obrar con entera libertad de acción, por estar supeditados a las empresas explotadoras de este negocio y a éstas no les conviene que se modifique el actual estado de cosas.

Por mi parte me creo libre de este tanto de culpa, puesto que en los pocos años que llevo interviniendo en cosas de manicomios, no he cesado nunca de trabajar para mejorar la triste condición de estos desgraciados enfermos y me cabe la satisfacción de manifestar que la Mancomunidad de Cataluña, con el buen criterio que le caracteriza, se ha dado cuenta de la necesidad de transformar completamente este servicio y ha acordado un plan de reorganización, siendo sus principales bases: primera, creación de un Hospital Mental para las psicosis agudas o de evolución relativamente corta, y para la enseñanza de la Psiquiatría; segunda, creación de varios Asilos-Colonias para los alienados crónicos; tercera, creación de Asilos especiales para atrasados, alienados difíciles, epilépticos, etc.

No se ha contentado la Mancomunidad con acordar el plan de reorganización; lo está llevando a la práctica con toda la rapidez que las circunstancias le permiten. Con este fin ha adquirido ya una hermosa finca en las cercanías de esta ciudad, de una extensión de más de 30 hectáreas y de una situación y orientación excelentes. Este extenso solar está destinado para el Hospital Mental; creo que no tardarán en hacerse públicas las bases del concurso de ante-proyectos para la construcción de dicho Hospital.

Como usted adivinará, en este Hospital el tratamiento de los enfermos se hará a base del encarnamiento, psicoterapia y baños, suprimiéndose de una manera absoluta toda clase de coerción mecánica.

Yo creo, amigo doctor, que habéis hecho bien en llevar este asunto a una revista popular, es necesario que médicos, publicistas y el público en general detenga su mirada en estos infelices y se preocupan de mejorar su suerte. Es necesario que todos nos hagamos cargo de que estos enfermos son más dignos aún, si cabe, de consideración que los demás enfermos de enfermedades comunes; que muchos de ellos por sus ideas de culpabilidad, de persecución, 0 por sus alucinaciones terroríficas sufren de una manera horrible; que la sensación de risa, de miedo, o de asco que estos enfermos generalmente producen, se convertiría en deseo de protección y de auxilio, si conociésemos sus pesadumbres. Es preciso que se comprenda que si bien debemos guardar ciertas precauciones con los enfermos de la mente, nunca debe ser éstas depresivo-s para los mismos ; por esto deben desaparecer los manicomios de altas murallas y de enrejadas ventanas; por esto deben desaparecer de los manicomios toda clase de instrumentos que signifiquen coerción o violencia. Es preciso que se sepa que el atar a un enfermo de la misma manera que se ata a un perro, en la anilla de una pared o en la pata de una mesa; que el atar a un pobre de estos desgraciados, de manos 0 de pies alegando sea cuál fuere el pretexto, o meterlo dentro de una apretada camisa de fuerza, no sirven para otra cosa que para aumentar la excitación del enfermo o para agravar algún repugnante vicio.

Si todos nos diésemos cuenta de que estos y otros procedimientos tan antihumanos $\mathrm{y}$ tan depresivos para el enfermo no son necesarios para mantener el orden en una casa de 
locos y que son altamente perjudiciales para la curación de la locura, de seguro qué no permitiríamos que en ninguno de nuestros manicomios se tratara así a nuestros semejantes.

Estimulemos, pues, si es preciso a la Mancomunidad de Cataluña, para que rápidamente lleve a feliz término su buena obra; llamemos la atención, a las demás corporaciones similares para que salgan de su letargo, y mientras tanto felicitémonos por el nuevo horizonte que empieza a divisarse para estos pobres enfermos.
Para terminar, querido doctor, le suplico me considere como buen amigo y que en estas líneas solamente vea un deseo de amistosa conversación sobre un asunto tan necesitado de atención cariñosa.

TOMÁS BUSQUET

Médico inspector del servicio de dementes de la Mancomunidad de Cataluña. Barcelona, Octubre de 1916.

Reimpreso de: Tomás Busquet. Manicomios españoles (Carta abierta al Dr. Gonzalo R. Lafora). España. 2 nov. 1916. 93: 14. 